
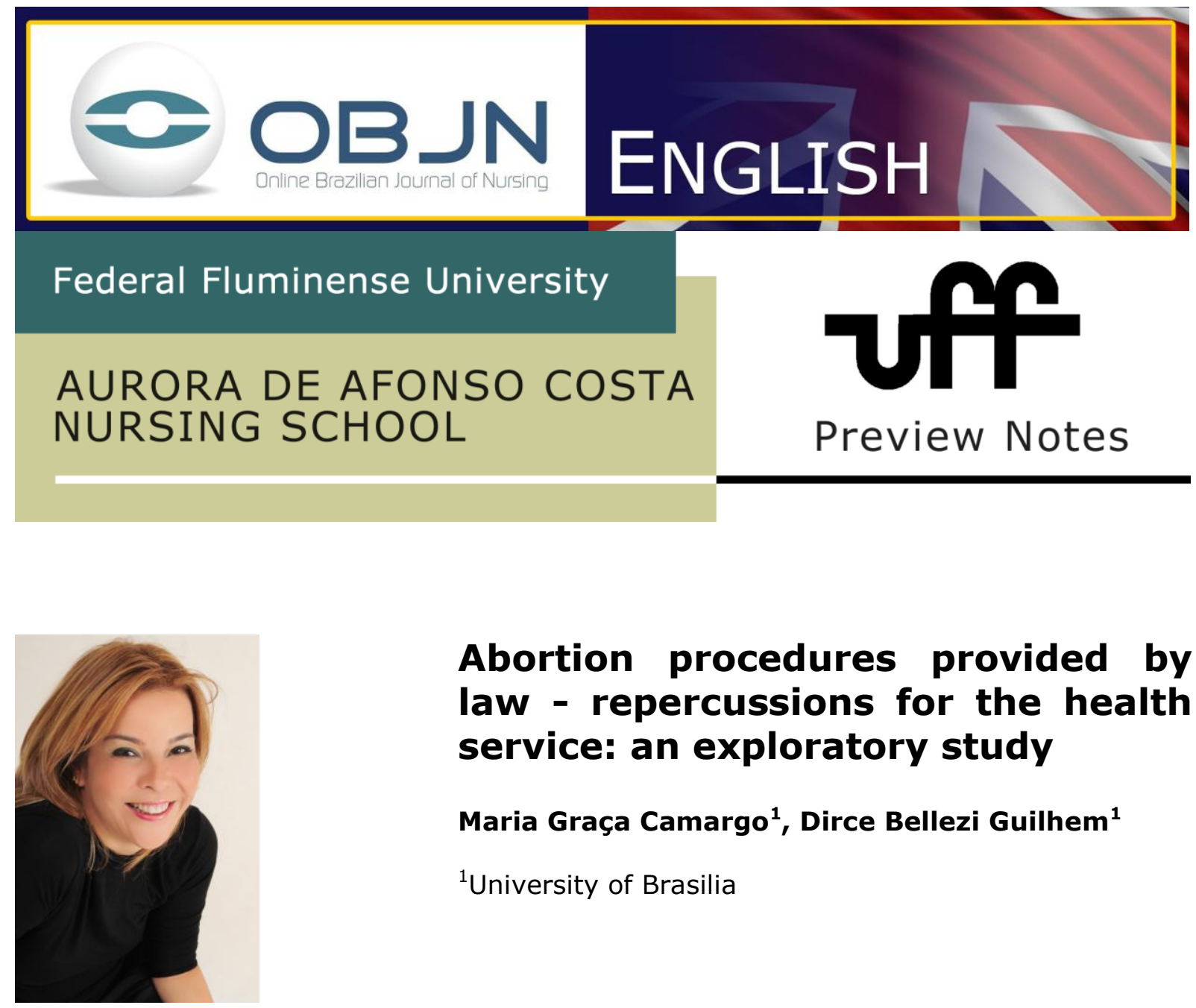

\title{
Abortion procedures provided by law - repercussions for the health service: an exploratory study
}

\author{
Maria Graça Camargo', Dirce Bellezi Guilhem ${ }^{1}$ \\ ${ }^{1}$ University of Brasilia
}

\begin{abstract}
Doctoral thesis developed in the Post-graduate in Nursing Program in the University of Brasilia. The main objective is: to describe the working process of a legal abortion service center in a regional hospital, located in Brasilia, Federal District. Method: this is a qualitative, descriptive and exploratory piece of research, with semi-structured interviews to collect data, using the technique of thematic content analysis to treat the information acquired.

Keywords: Sexual Violence; Legal, Abortion; Health Personnel; Health Knowledge, Attitudes e Practice.
\end{abstract}




\section{PROBLEM SITUATION AND ITS SIGNIFICANCE}

Contemporary societies are characterized by moral pluralism and the defense of a secular State, including a vast array of moral diversity. Brazil follows such a positioning, and now has to deal with emerging conflicts from a range of different origins. The interruption of pregnancy, whether or not related to sexual violence, it one of those conflicts this society has to deal with on a daily basis.

During a pregnancy originating from sexual violence, women and teenagers are permitted the consider a legal interruption up to the twentieth week $^{(1)}$. During this process, supported by the Code of Ethics, the health professional can refuse to participate in the process of legal abortion if this decision does not interfere with the right of the patient to have medical assistance during the abortion.

This legal tool, called objection of conscience, is used by health professionals when their personal beliefs and moral standards are against the proceedings used when taking care of the population, especially in situations related to the beginning and the end of life. It can be considered to be a victory for a pluralist and tolerant society that respects cultural diversities and individual convictions ${ }^{(2)}$. Therefore, it is a strategy that shows respect for the users and for the professionals involved.

Situations related to the objection of conscience and its influence on many aspects of life in society - and not only in health service centers - are objects of debate in Europe, North America and Oceania. However, this is a topic that has moved slowly in Brazilian society, both in science and health care. The main discussions are linked to the legal interruption of pregnancy, aggressive medical treatment and the circumstances connected to the end of life.

The Special Department for Policies for Women reveals that, in 2010, Brazil had 441 centers to provide help to women who have suffered sexual violence. Of these, 60 are ready to perform abortions in accordance with the $\operatorname{law}^{(3)}$. To date, there have been no scientific reports on the use of objection of conscience by health staff that could have led 
to the failure to provide any sort of healthcare to the women and/or teenagers who requested this type of procedure.

\section{OBJECTIVES}

General: To examine and describe the work developed by an abortion service center, in accordance with Brazilian law, in a public hospital in Brasilia.

Specific: to characterize the socio-demographic profile of the permanent and supporting healthcare teams that work in this area; to characterize the socio-demographic profile of adolescents and women who require the services of these centers; to identify the conceptions about abortion as it is described by law, and the motivations of these health professionals and specifically, what makes them work in this area; to analyze the preparation that the health professionals undertake in order to work with women and adolescents who require abortions as provided by law, and the impact on the healthcare service provided to such patients; to verify if the health professionals who work in this area are clear about the objection of conscience aspect and its influence in their work; to analyze the perception of adolescents and women about the healthcare received, from the initial reception to the performance of the abortion as provided by law.

\section{METHOD}

This is an exploratory piece of descriptive research, which uses a qualitative methodology. Emphasis has been placed on the thematic content analysis of the collected data. Three distinct groups will be invited to participate: the permanent multidisciplinary team, responsible for receiving and directing the healthcare provided to women and adolescents; the health team that provides support and carries out the abortion as provided by law; and the adolescents and women who seek the services of a health center in order to solve the problem they are faced with. 
For the collection of data, three instruments will be used: the first is a guide used at the beginning of the interview which includes closed questions related to the sociodemographic characteristics of both groups of health professionals and the adolescents and women who use the service. The second includes an itinerary of open questions, directed to the interviews with the professionals of the permanent and support health teams. The third, involves interviews with women and adolescents, to be performed in a particular sequence according to the protocol of the 2010 technical regulations of the Brazilian Ministry of Health. These will take place on reception into the center, during the period of multi-professional support, after the patient has signed an agreement in terms of the termination of the pregnancy, and after the legal interruption of the pregnancy.

Project 356/2011 was approved by the Ethics in Research Committee of the State Department of Health of the Federal District, under notion 0475/2011, based on Resolution 196/96, of the Brazilian National Health Council.

\section{REFERENCES}

1. Moura LBA, Reis PED, Faustino AM, Guilhem D, Bampi LNS, Martins G. Vivências das violências experimentadas por mulheres do Distrito Federal: estudo descritivo. Online braz J nurs (serial in the Internet). 2011 [cited 2012 may 20]; 10(3). Available from: http://www.objnursing.uff.br/index.php/nursing/article/view/3534.

2. Porto R. Objeção de consciência, aborto e religiosidade: práticas e comportamentos dos profissionais de saúde em Lisboa. Rev Estud Fem. 2008; 16(2): 661-6.

3. Ministério da Saúde (BR). Secretaria de Políticas para Mulheres. Brasília: Ministério da Saúde; 2010.

\section{Approved: 17/06/2012}

Received: 10/09/2012 